\title{
EPIDEMIOLOGY OF SWINE TRICHINELLOSIS in the Republic of Croatia
}

\author{
MARINCULIĆ A.*, GAŠPAR A.**, DURAKOVIĆ $*$ E., POZIO E.*** \& LA ROSA G.***
}

\section{Summary :}

In order to study the epidemiology of trichinellosis with special emphasis on swine a detailed study was performed. The goals of the study were to define the prevalence of trichinellosis in swine and rats and to determine the etiological agents of the disease with special emphasis on sylvatic species, Trichinella britovi. Considering the obtained data it can be concluded that the risk of Trichinella infection for swine in endemic areas in Croatia is rather high today. On the contrary, a sharp decline in human cases is registered what is certainly a result of obligatory trichinelloscopy even for private purposes. The parasite was found to be prevalent in rats too. Studies on genotypes suggest that Trichinella spiralis is the most prevalent etiological agent of domestic trichinellosis in Croatia, even so the sylvatic species Trichinella britovi can be also present in the domestic habitat suggesting a link between the sylvatic and domestic cycle.

KEY WORDS : Trichinella, epidemiology, Croatia, genotyping

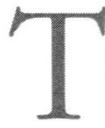

richinellosis is still the most important public health concern in Croatia.

In the past, trichinellosis was confined to just a few villages. According to the study (data from previous investigations) performed in 1988 in the District of Vukovar, the prevalence rate of trichinellosis in swine was very low $(0,05 \%)$. The disease was caused by a few premises with low bio-sanitary conditions and in pigs with grazing habits. Due to uncontrolled migration of people and animals caused by war conflicts the trichinellosis spread to other neighbouring areas in which outbreaks were completely unknown. In order to prevent any infection in humans the Ministry of Agriculture and Forestry promulgated a decree of obligatory trichinelloscopy for swine slaughtered under all

\footnotetext{
* Veterinary Faculty, University of Zagreb, Heinzelova 55, Zagreb, Republic of Croatia.

** Ministry of Agriculture and Forestry Republic of Croatia, Zagreb, Republic of Croatia.

${ }^{* * *}$ Istituto Superiore di Sanita, Viale Regina Elena 299, Rome, Italy.
}

Correspondence: A. Marinculić. Department of Parasitology and Parasitic Diseases, Veterinary Faculty University of Zagreb, Heinzelova 5510000 Zagreb, Croatia.

Tel. : 00385012390362 - Fax : 00385012441390

E-mail : albert@vef.hr conditions including private slaughter. From 1996, the Ministry also encouraged large scale surveys in swine of which results are presented in this study. The goals of the suveys were to define: the prevalence of trichinellosis in swine according to parasitological and serological examinations; the prevalence in rats trapped in incriminated farms; the etiological agents of the disease with special emphasis on the sylvatic species Trichinella britovi.

\section{MATERIALS AND METHODS}

\section{TRICHINELLOSIS IN RATS}

The prevalence was estimated in rats trapped in seven different farms from two different areas (Table II). After grinding, $10 \mathrm{~g}$ of muscle tissue were digested and the presence of larvae was determined for each rat.

\section{TRICHINELLOSIS IN PIGS}

The prevalence data were collected from reports of our laboratory and all veterinary services in endemic districts. Blood samples were collected from sows of various ages. Totally 475 sows were tested from 100 herds distributed in all districts with trichinellosis. Sera were tested by ordinary ELISA and results were evaluated as describe by Gamble et al. (1999) using ES antigen.

\section{PCR ANALYSIS}

Forty muscle larvae of Trichinella from each of 18 positive pigs raised in incriminated farms among four villages in the District of Vukovar were identified by a multiplex PCR analysis (Zarlenga et al., 1999).

\section{RESULTS}

T $\mathrm{t}$ has to be stressed that trichinellosis in humans in our country is still present but there is a sharp 1 decline in human cases in 2000 (Table I). The 


\begin{tabular}{lrrrc}
\hline District & $\mathbf{1 9 9 7}$ & $\mathbf{1 9 9 8}$ & $\mathbf{1 9 9 9}$ & 1.1.- 1.4. 2000 \\
\hline 1 Vukovar & 17 & 327 & 51 & 23 \\
2 Osijek & 3 & 52 & 29 & - \\
3 Slavonski Brod & 10 & 11 & 22 & - \\
4 Virovitica & 57 & 26 & 15 & - \\
Total & 112 & 575 & 337 & 23 \\
\hline
\end{tabular}

Data obtained from the Croatian Department of Public Health.

Table I - Patients affected by trichinellosis during the period from 1997 up to 2000 in four different endemic districts.

\begin{tabular}{lcccc}
\hline District & Farm & $\begin{array}{c}\text { No of exa- } \\
\text { mined rats }\end{array}$ & $\begin{array}{c}\text { No of } \\
\text { positives }\end{array}$ & $\begin{array}{c}\text { Preva- } \\
\text { lence } \%\end{array}$ \\
\hline 1 Vukovar & 1 & 20 & 12 & 60,0 \\
& 2 & 12 & 12 & 80,0 \\
2 Osijek & 3 & 11 & 11 & 61,10 \\
\end{tabular}

Table II. - The prevalence of Trichinella in rats trapped in small pig farms with high prevalence.

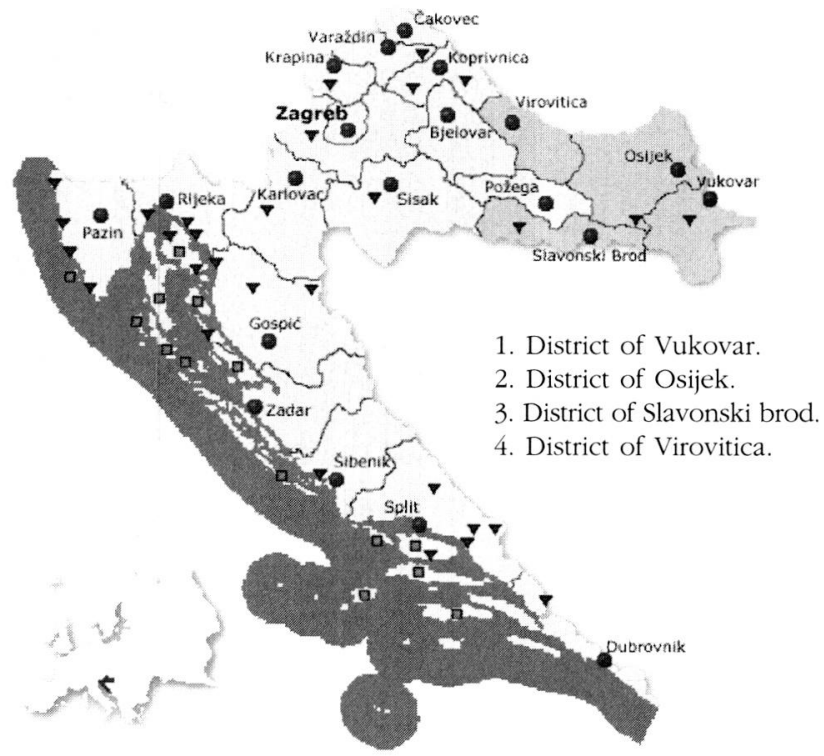

Fig. 1. - Endemic trichinellosis districts.

\begin{tabular}{lccccc}
\hline District & $\begin{array}{c}\mathbf{1 9 9 5} \\
\text { examined/ } \\
\text { positive }\end{array}$ & $\begin{array}{c}\mathbf{1 9 9 6} \\
\text { examined/ } \\
\text { positive }\end{array}$ & $\begin{array}{c}\mathbf{1 9 9 7} \\
\text { examined/ } \\
\text { positive }\end{array}$ & $\begin{array}{c}\mathbf{1 9 9 8} \\
\text { examined/ } \\
\text { positive }\end{array}$ & $\begin{array}{c}\mathbf{1 9 9 9} \\
\text { examined/ } \\
\text { positive }\end{array}$ \\
\hline 1 Vukovar & $33480 / 87$ & $34903 / 195$ & $83946 / 979$ & $117768 / 1385$ & $162441 / 2478$ \\
2 Osijek & $4774 / 5$ & $4460 / 4$ & $35891 / 90$ & $83116 / 275$ & $137579 / 708$ \\
3 Slavonski Brod & $1145 / 4$ & $2414 / 5$ & $13248 / 37$ & $37878 / 62$ & $56767 / 275$ \\
4 Virovitica & $0 / 0$ & $0 / 0$ & $12700 / 60$ & $35193 / 201$ & $51908 / 434$ \\
\hline
\end{tabular}

Table III. - The prevalence of Trichinella in swine slaughtered in four endemic districts during the period from 1995 up to 1999

highest prevalence in humans was observed in the District of Vukovar which was previously regarded as an endemic region (Fig. 1). Interestingly, up to 1997, trichinellosis was not present (data not shown) in the District of Virovitica (Table III). Immigrant refugees from an endemic region (District of Vukovar) for the significant spread were found as cause. Within one year, trichinellosis spread out significantly and became an important problem. From a total of 475 sera collected from sows, 27 sera were positive with a prevalence of $5.5 \%$ (Table IV). Significant differences were found among prevalence between different districts which varied from $2.0 \%$ up to $10.0 \%$. In a pig herd, seroprevalence ranged from $10 \%$ up to $33.3 \%$ (data not shown).

\begin{tabular}{lccc}
\hline \multicolumn{1}{c}{ District } & $\begin{array}{c}\text { No } \\
\text { of } \\
\text { herds }\end{array}$ & $\begin{array}{c}\text { No of } \\
\text { examined } \\
\text { sows }\end{array}$ & $\begin{array}{c}\text { Sero- } \\
\text { preva- } \\
\text { lence } \%\end{array}$ \\
\hline 1 Vukovar & 48 & 190 & 10,0 \\
2 Osijek & 27 & 150 & 2,6 \\
3 Slavonski Brod & 15 & 85 & 3,5 \\
4 Virovitica & 10 & 50 & 2,0 \\
\hline
\end{tabular}

Table IV. Seroprevalence of trichinellosis in tested sows.
Among rats trapped in seven farms a very high prevalence rate of the parasite was registered (Table II). In one farm (No 2), $80.0 \%$ of rats were found infected. Some of them harboured more than 200 larvae per gram of musculature (data not shown).

Multiplex PCR analysis revealed that out of 18 samples examined T. spiralis alone was present in most animals (16 samples of infected muscle or $89.0 \%$ ) (Fig. 2). Trichinella britovi was identified in one pig (5.5\%). Both species were detected in another case (5.5\%).

\section{DISCUSSION}

1 The epidemiology of trichinellosis in swine has considerably changed in the last decade in Croatia. In the past, trichinellosis was mostly present in pigs reared under seasonal grazing condition. Rapić et al. (1984) found a rather high prevalence with quite low intensity of infection. On the contrast, the prevalence of trichinellosis in pigs at small private rural farms was relatively low comparing to grazing animals, but the intensity of infection was very high. The rats from small private rural farms were only moderately 


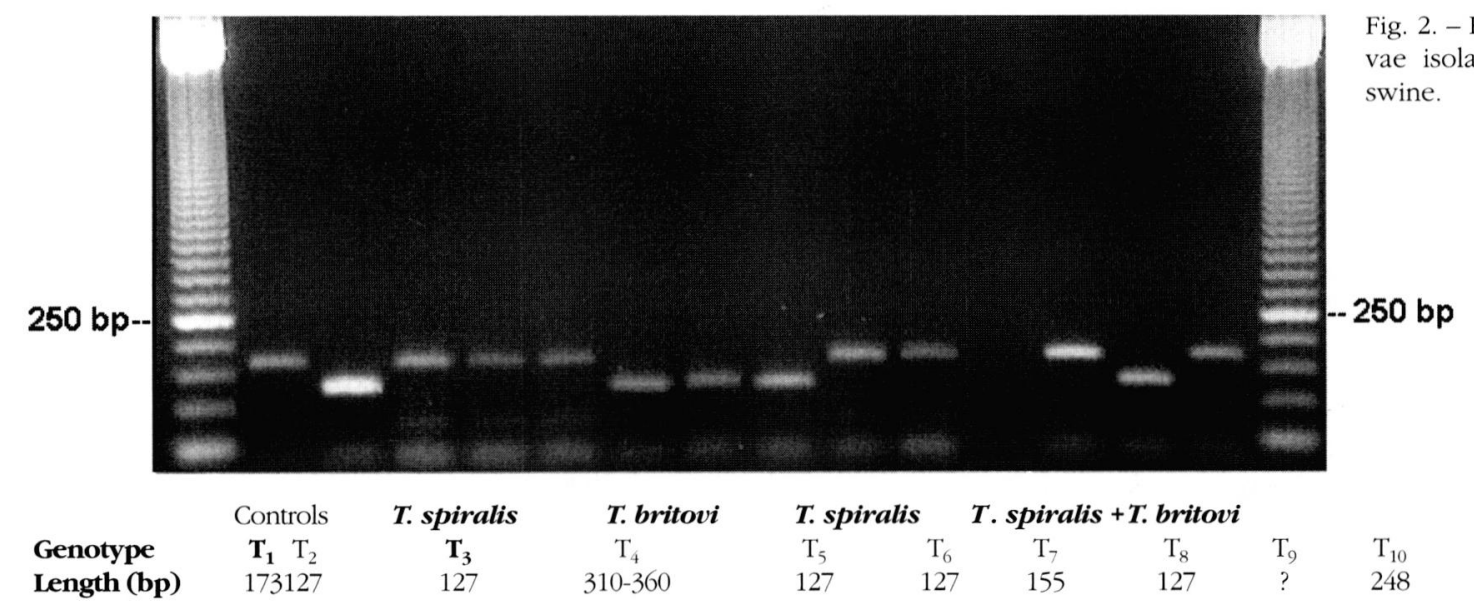

Fig. 2. - PCR analysis of larvae isolated from infected wine.

\section{$50 \mathrm{bp}$}

infected. Among them authors found just $10.7 \%$ be easilly correlated to the prevalence of infected rats infected.

Human cases of trichinellosis were mainly reported from outbreaks in the District of Vukovar which was the only endemic district at that time. Today, human cases are distributed in all districts as in pigs (Table I). As it is shown in table III, in the period up to 1997, the District no 4 were completely out of any control. The decree of obligatory trichinelloscopy was not promulgated for this region. Due to the uncontrolled migration of people that raise pigs a significant increase in infections in the same area was noted in a period of just one year.

Considering the data and facts above it can be concluded that the risk of Trichinella infection for swine in endemic areas in Croatia is rather high today. On the contrary, a sharp decline in human cases is registered what is certainly a result of obligatory trichinelloscopy even for private purposes, especially in case of in home preparation of meat products. Besides that, the results compared with previous studies performed in the same area (Rapić et al. 1984), indicate that the prevalence of Trichinella among rats dramatically increased. The high prevalence in rats suggests that the infection pressure is very high and that these animals can serve as important reservoirs of trichinellosis. Murrell et al. (1984) unequivocally demonstrated that confinement reared grain fed hogs, readily eat rat carcasses. They concluded that in every instance, transmission of trichinae to the hogs occurred, even with lightly infected rats. The seroprevalence of trichinellosis in tested sows ranged from $2.0 \%$ up to $10.0 \%$ depending on the district (Table IV). The highest seroprevalence among sows from the District 1 was found. In this study, we have shown hat the seroprevalence in sows in the same District substantially increased according to the results published by Rapić et al. (1984). It has to be stressed that the same author performed some of his surveys in the same area that was chosen in our studies. The highest seroprevalence in sows can trapped in some farms from the same District (Table II). Studies on genotypes suggest that Trichinella spiralis is the most prevalent etiological agent of domestic trichinellosis in Croatia, even so the sylvatic species Trichinella britovi can be also present in the domestic habitat suggesting a link between the sylvatic and domestic cycle. (Pozio et al., 1997; Pozio et al., 1998). The presence of different etiological agents in the same host suppose the hypothesis that an animal can acquire more than one infection during its life span.

\section{REFERENCES}

Gamble H.R. \& Bush E. Seroprevalence of Trichinella infection in domestic swine based on the National Animal Health Monitoring Systems 1990 and 1995 swine surveys. Veterinary Parasitology, 1999, 80, 303-310.

Murrell K.D., Gamble H.R. \& Schad G.A. Experimental transmission of Trichinella spiralis to swine by infected rats. Proceedings of the Helminthological Society, Washington 1984, 51, 66-68.

Pozio E., Miller I., Jarvis T. \& Kapel C.M. \& La Rosa G. Distribution of sylvatic species of Trichinella in Estonia according to climate zones. Journal of Parasitology, 1998, 84, 193-195.

Pozio E., Serrano F.J., La Rosa G., Reina D., Perez Maritin E. \& NAvarrete I. Evidence of potential gene flow in Trichinella spiralis and in Trichinella britovi in nature. Journal of Parasitology, 1997, 83, 163-166

Rapić D., Wikerhauser T., Džakula N., Stojčević D. Seroepizootiological studies on trichinellosis by the ELISA in pigs in Yugoslavia, in: Proceedings of the Sixth International Conference on Trichinellosis (ed) Kim C.W., 1984, 128-132

Zarlenga D.S., Chute M.B., Martin A. \& Kapel C.M. A multiplex PCR for unequivocal differentiation of all encapsulated and non encapsulated genotypes of Trichinella. International Journal of Parasitology, 1999, 25, 1859-1867. 